\title{
Parenteral prostanoids for severe Group 3 pulmonary hypertension with right ventricular dysfunction
}

\author{
Colin A. Hinkamp ${ }^{1}$, Trushil Shah ${ }^{2}$, Sonja Bartolome ${ }^{2}$, Fernando Torres ${ }^{2}$, Kelly M. Chin ${ }^{2}$ \\ ${ }^{1}$ Department of Internal Medicine, University of Texas Southwestern Medical Center, Dallas, TX, USA; ${ }^{2}$ Division of Pulmonary and Critical Care \\ Medicine, Department of Internal Medicine, University of Texas Southwestern Medical Center, Dallas, TX, USA \\ Contributions: (I) Conception and design: T Shah, S Bartolome, F Torres, KM Chin; (II) Administrative support: T Shah, S Bartolome, F Torres, \\ KM Chin; (III) Provision of study materials or patients: All authors; (IV) Collection and assembly of data: All authors; (V) Data analysis and \\ interpretation: All authors; (VI) Manuscript writing: All authors; (VII) Final approval of manuscript: All authors. \\ Correspondence to: Colin A. Hinkamp, MD. Department of Internal Medicine, University of Texas Southwestern Medical Center, 5323 Harry Hines \\ Blvd., Dallas, TX 75390-9030, USA. Email: colin.hinkamp@utsouthwestern.edu.
}

Background: Group 3 pulmonary hypertension $(\mathrm{PH})$ is a common complication in patients with lung diseases but there are currently no FDA-approved therapies. The data is conflicting, but a few small studies suggest potential benefits in using Group $1 \mathrm{PH}$ therapies in these patients, particularly in severe $\mathrm{PH}$ with right ventricular (RV) dysfunction.

Methods: A retrospective cohort study of patients with severe Group $3 \mathrm{PH}$ with RV dysfunction who received parenteral prostanoids from 2007-2018 at our institution was undertaken. Severe $\mathrm{PH}$ was defined as mean pulmonary arterial pressure (mPAP) $\geq 35 \mathrm{mmHg}$ or mPAP 25-34 with cardiac index (CI) $<2.4 \mathrm{~L} / \mathrm{min} / \mathrm{m}^{2}$. Routine prognostic studies including $\mathrm{N}$-terminal prohormone of brain natriuretic peptide (NT-proBNP), 6-minute walk distance (6MWD), WHO Functional Class assessment, oxygen requirement, arterial oxygen saturation, right ventricular systolic pressure (RVSP) and right heart catheterization (RHC) pressures, were obtained before initiation of parenteral therapy and at first clinical follow-up.

Results: Nine patients were included. Five were female (55.6\%) with a median [interquartile range (IQR)] of 69 [54-71] years. Median CI was $1.8(1.6-2.4) \mathrm{L} / \mathrm{min} / \mathrm{m}^{2}$ and median pulmonary vascular resistance (PVR) was 14.7 (10.7-17.1) Wood units (WU). We found no statistically significant improvement in NTproBNP levels, exercise capacity, or functional class. Resting oxygen requirement worsened from 4 to $6 \mathrm{~L} / \mathrm{min}(\mathrm{P}=0.04)$ and exertional oxygen saturation nadir worsened from $90 \%$ to $83 \%(\mathrm{P}=0.01)$ despite the increase in $\mathrm{FiO}_{2}$ with exertion. Overall results were heterogenous: several patients demonstrated clinical stabilization, with two undergoing lung transplantation and one showing long-term stability with medical therapy. Symptoms remained severe for most: three patients discontinued prostanoid therapy, choosing to pursue hospice care.

Conclusions: We found no statistically significant improvement in NT-proBNP levels, exercise capacity, or functional class, while oxygen requirement at rest and oxygen saturation during exertion significantly worsened. Our results suggest that parenteral prostanoids should not generally be considered in the treatment of Group $3 \mathrm{PH}$ patients.

Keywords: Prostanoids; prostaglandins; lung transplantation; hypoxemia; pulmonary hypertension (PH)

Submitted Apr 12, 2020. Accepted for publication Oct 22, 2020.

doi: $10.21037 /$ jtd-20-1635

View this article at: http://dx.doi.org/10.21037/jtd-20-1635

(c) Journal of Thoracic Disease. All rights reserved. 


\section{Introduction}

Pulmonary hypertension $(\mathrm{PH})$ is a common complication of long-standing lung disease (Group $3 \mathrm{PH}$ ), and is associated with decreased functional status, increased oxygen requirement, and increased mortality (1-6). There has been significant growth in therapeutic options for Group 1 pulmonary arterial hypertension (PAH) over the past 2 decades, but these medications have not been approved for use in Group $3 \mathrm{PH}$. Reversal of hypoxia and treatment of the underlying lung pathology, when possible, are often the only treatment options. Lung transplantation is typically recommended for those who are eligible $(7,8)$. Despite the lack of compelling data for the use of Group $1 \mathrm{PAH}$ medications in Group $3 \mathrm{PH}$, up to $80 \%$ of physicians at $\mathrm{PH}$ referral centers report considering these medications in at least some Group $3 \mathrm{PH}$ patients (9). Treatment is particularly challenging for patients with severe right ventricular (RV) failure, and overall outcomes are poor (10-12).

Among the most potent Group $1 \mathrm{PAH}$ medications are parenteral prostanoids. Released in-vivo by endothelial cells, prostanoids act primarily as pulmonary vasodilators but also have anti-thrombotic and anti-proliferative properties (13). When administered parenterally they cause significant non-selective pulmonary vasodilation and have been shown to significantly improve symptom burden and hemodynamics in Group 1 PAH (14). However, as nonselective pulmonary vasodilators, they can potentially lead to worsened hypoxemia by reversing hypoxia-related vasoconstriction. The worsening of hypoxemia is viewed by some as a contraindication for use with Group $3 \mathrm{PH}$ patients, who already suffer from lung-disease related hypoxemia. In a 2014 pilot study utilizing parenteral treprostinil in patients with advanced Group $3 \mathrm{PH}$ with $\mathrm{RV}$ dysfunction, there was significant improvement in right heart hemodynamics and RV function on echocardiogram without impacting arterial oxygen saturation (15). This suggests some degree of clinical equipoise for additional research on the use of prostanoid therapies for Group 3 patients, at least in this subset of very severe $\mathrm{PH}$ with $\mathrm{RV}$ dysfunction where oxygen delivery is restricted by both hypoxic lung disease as well as limited cardiac output (15). We present a retrospective cohort study, in accordance with the STROBE guidelines, of patients at our PH referral center with severe Group $3 \mathrm{PH}$ with RV dysfunction who were treated with parenteral prostanoids, with respect to hemodynamics, biomarkers, oxygenation status, functional capacity, and survival. We present the following article in accordance with the STROBE reporting checklist (available at http://dx.doi.org/10.21037/jtd-20-1635).

\section{Methods}

\section{Patient selection}

This study was a retrospective cohort study that included all patients with severe Group $3 \mathrm{PH}$, defined as mean pulmonary arterial pressure $(\mathrm{mPAP}) \geq 35 \mathrm{mmHg}$ or mPAP $25-34$ with cardiac index $(\mathrm{CI})<2.4 \mathrm{~L} / \mathrm{min} / \mathrm{m}^{2}$ on right heart catheterization (RHC). Patients were included if they had a qualifying lung disease, such as idiopathic pulmonary fibrosis (IPF) or combined pulmonary fibrosis and emphysema (CPFE), along with severe abnormalities on spirometry [forced vital capacity (FVC) or forced expiratory volume in 1 second $\left(\mathrm{FEV}_{1}\right)<50 \%$ predicted], or diffuse lung disease on imaging plus a diffusion limitation of carbon monoxide (DLCO) $<50 \%$ predicted. In addition, patients were required to have initiated intravenous epoprostenol or intravenous or subcutaneous treprostinil between 2007 and 2018 at the University of Texas Southwestern Medical Center. Both treatment naïve and patients previously started on other $\mathrm{PH}$-specific therapies were included, which may be a potential confounder. Patients starting parenteral therapy within 2 weeks or less of starting an oral therapy were considered treatment naïve. The $\mathrm{PH}$ evaluation included an echocardiogram, RHC, pulmonary function tests (PFTs) and ventilation-perfusion scan, as well as additional tests when indicated. Institutional review board approval was obtained from the University of Texas Southwestern Medical Center Human Research Protection Program (\#052015-041), including a waiver of informed consent. The study was conducted in accordance with the Declaration of Helsinki (as revised in 2013).

\section{Data acquisition}

Results from routine prognostic studies obtained prior to initiation of parenteral therapy and at first clinical followup were recorded. These studies included $\mathrm{N}$-terminal prohormone of brain natriuretic peptide (NT-proBNP) level, 6-minute walk test (6MWT), WHO Functional Class assessment, oxygen requirement, arterial oxygen saturation, echocardiography measuring right ventricular systolic pressure (RVSP), and RHC measuring right atrial pressure (RAP), mPAP, CI, and pulmonary capillary wedge pressure (PCWP). Oxygen requirement and arterial oxygen 
saturation data were acquired at the beginning and during $6 \mathrm{MWT}$, at rest and with exertion.

\section{Statistical analysis}

Continuous variables were described as median and interquartile range (IQR), unless otherwise stated. Changes between baseline at initiation of parenteral therapy and clinical follow-up were compared using the Wilcoxon signed-rank test. For the survival assessment, patients were censored at the time of transplantation. A KaplanMeier curve was created for visualization of survival time; statistical analysis was not performed. Statistical analyses were conducted with NCSS V.11 (NCSS LLC, Kaysville, UT, USA) and $\mathrm{P}$ values $<0.05$ were considered statistically significant.

\section{Results}

The study population consisted of nine consecutive patients with Group $3 \mathrm{PH}$ who were initiated on parenteral prostanoids between 2007 and 2018. There were 5 women (55.6\%) with a median age of 69 (range, 54-70) years. Lung function at baseline was variable; 3 had an FVC or $\mathrm{FEV}_{1}<50 \%$ predicted, while 6 had an FVC and $\mathrm{FEV}_{1}$ $>50 \%$ combined with a DLCO $<20 \%$ predicted and diffuse lung disease on imaging. Clinical narratives are shown in Table 1. Patients received intravenous epoprostenol $(\mathrm{n}=5)$, intravenous treprostinil $(\mathrm{n}=2)$, or subcutaneous treprostinil $(\mathrm{n}=2)$. At the time of parenteral prostanoid initiation, five patients were treatment naïve, two were receiving oral therapies including phosphodiesterase-5 inhibitors (PDE5is) and endothelin receptor antagonists (ERAs), and two patients were receiving triple therapy including a nonparenteral prostanoid (Table 1).

At first follow-up, there was no significant change in functional class, RVSP by echocardiogram, NT-proBNP level or 6-minute walk distance (6MWD). Due to patient mortality, repeat RHC was only available in four patients and thus statistical testing was not performed; however, a decrease in pulmonary vascular resistance (PVR) and an increase in CI was seen in all four patients (Figure 1 and Table 2). All but one patient was oxygen-dependent at the time of prostanoid initiation, and this tended to worsen during follow-up (Table 3). Specifically, resting oxygen requirement increased from a median of 4 to $6 \mathrm{~L} / \mathrm{min}(\mathrm{P}=0.04)$, exertional oxygen requirement increased from a median of 6 to $8 \mathrm{~L} / \mathrm{min}$ $(\mathrm{P}=0.06)$ and oxygen saturation nadir during exertion declined from a median of $90 \%$ to $83 \%(\mathrm{P}=0.01)$, despite the increase in $\mathrm{FiO}_{2}$ with exertion (Figure 2).

Median survival free from lung transplantation from the time of parenteral prostanoid initiation was 609 days (Figure 3). Only three patients were deemed eligible for lung transplantation, two of whom underwent lung transplantation during follow-up while one patient died 23 days after prostanoid initiation. A fourth patient who was actively listed at the time severe $\mathrm{PH}$ was diagnosed was removed from the transplant list due to frailty, deconditioning and a marginal increase in creatinine. Reasons for transplant ineligibility for the remaining patients are listed in Table 1. Three patients transitioned to hospice care due to a combination of persistent severe dyspnea, high $\mathrm{FiO}_{2}$ requirement limiting all activity, and prostacyclin associated side effects such as headache, nausea, reduced appetite and diarrhea; all three died within weeks of beginning prostacyclin down-titration.

\section{Discussion}

In this retrospective cohort study, we evaluated the effects of parenteral prostanoids on hemodynamics, biomarkers, oxygenation, and functional capacity in patients with severe Group $3 \mathrm{PH}$ and severe right heart dysfunction. We found no statistically significant improvement in NT-proBNP levels, exercise capacity, or functional class, while oxygen requirement at rest and oxygen saturation during exertion significantly worsened. However, overall results were heterogenous, and among those undergoing catheterization, hemodynamics generally improved. Several patients demonstrated clinical stabilization, including two who subsequently underwent lung transplantation and one with satisfactory symptom control and long-term stability with medical therapy.

Symptoms remained severe for most patients, with all patients remaining functional class III or IV at first followup and three patients eventually choosing to pursue hospice care. All three noted both significant prostanoid-associated side effects, such as headache, nausea and diarrhea, as well as severe dyspnea. Oxygenation was also noted to have worsened for many patients, both at rest and during exertion. We speculate that prostanoid therapy contributed to their hypoxia, due to worsened ventilation-perfusion mismatch. Although progression of the underlying lung diseases is also possible, PFTs remained stable in most patients throughout follow-up. PAH therapies can worsen hypoxemia through non-selective pulmonary vasodilation, particularly in patients 


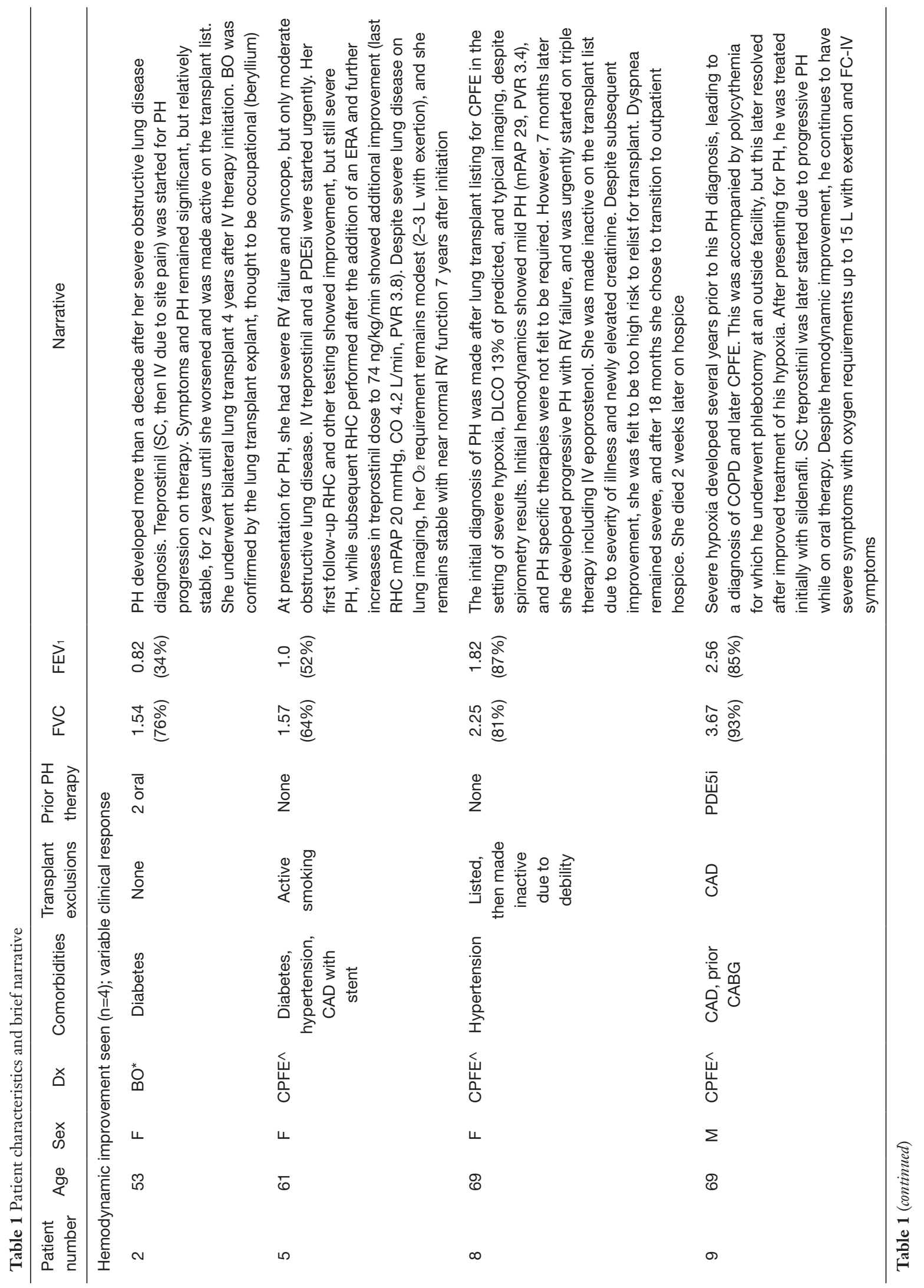




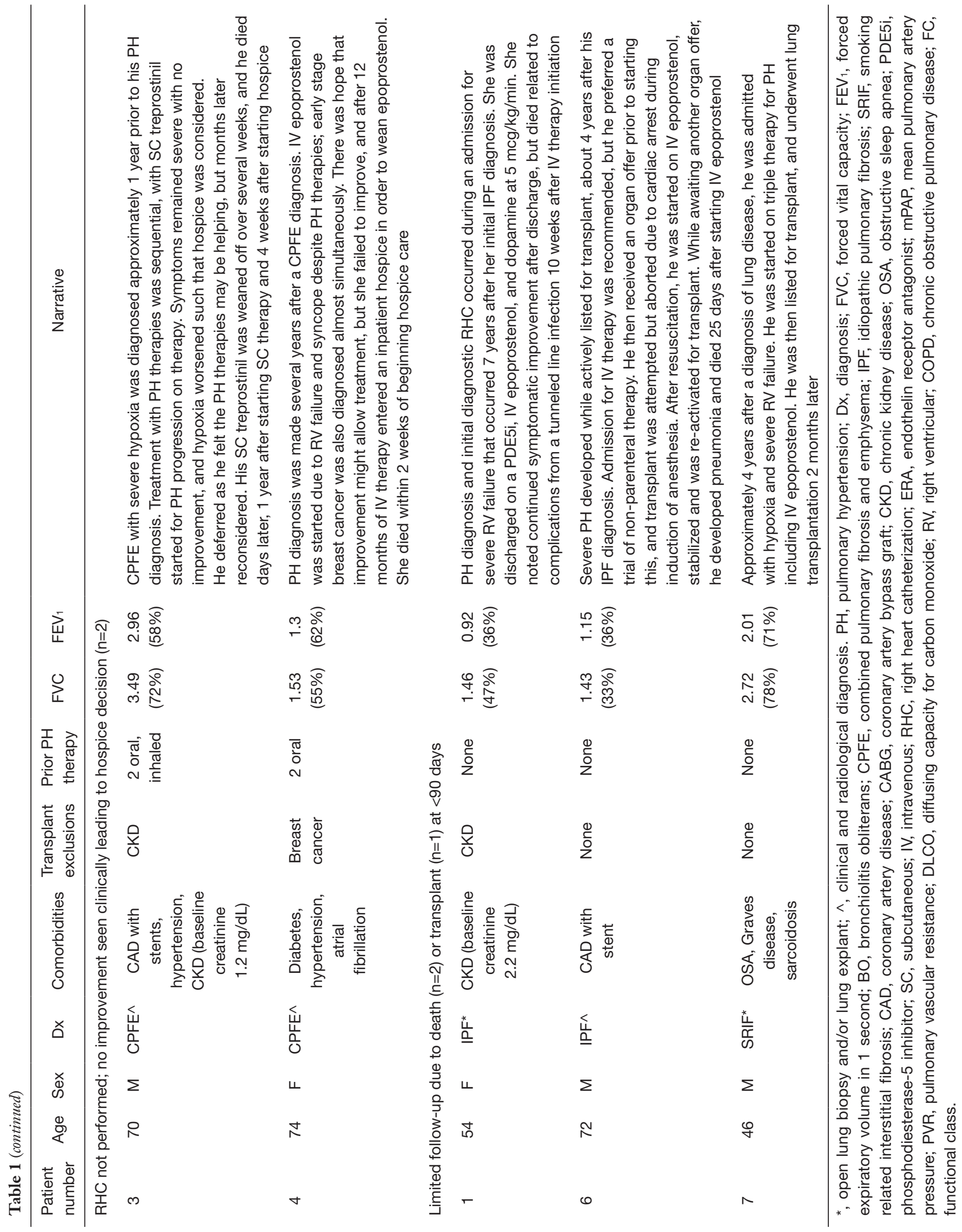



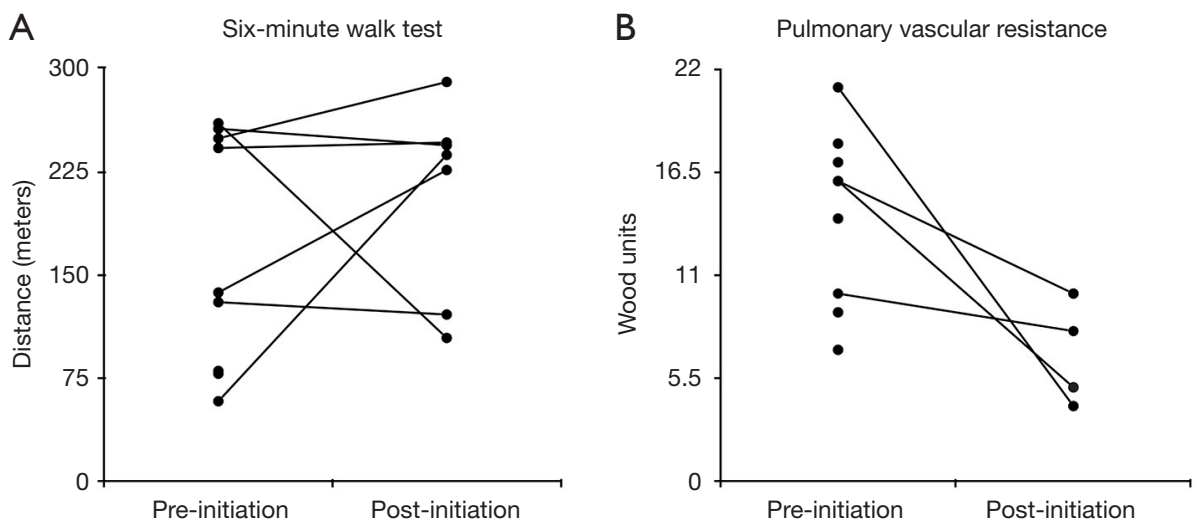

Figure 1 Clinical data obtained at initiation of parenteral prostanoids and at first clinical follow-up. (A) 6MWT distance in meters; (B) PVR, in WU, by RHC. 6MWT, 6-minute walk test; PVR, pulmonary vascular resistance; WU, Wood units; RHC, right heart catheterization.

with lung disease. Parenteral prostanoids may be more likely to cause hypoxemia as opposed to other PAH therapies, based on short-term studies showing greater increases in shunt fraction and ventilation-perfusion mismatch relative to inhaled prostanoids (16), oral PDE5is (17), and ERAs (18). Although the effects on oxygenation for many patients were modest, the median supplemental oxygen requirement at rest increased from 4 to $6 \mathrm{~L} / \mathrm{min}$, moving most patients outside the range of what many portable concentrators can deliver.

This finding adds to other evidence suggesting caution when considering $\mathrm{PH}$ therapies in this patient population. However, these results must also be considered in the context of the overall clinical setting. Right heart function was severely impaired in many patients, and one goal of therapy was to achieve sufficient stabilization such that lung transplantation evaluation and listing could be accomplished. Further, from an oxygen delivery standpoint, a modest decline in systemic oxygenation may be acceptable as long as it is not severe and cardiac output increases sufficiently such that overall oxygen delivery is preserved or increases. Notably, a similar trade-off is considered with atrial septostomy in end-stage PAH patients. A separate concern is the low rate of transplant eligibility. One might argue that parenteral prostanoids should only be considered in patients highly likely to be eligible for lung transplantation. However, eligibility is often not clear at the time of initiation. For example, active smokers who are able to quit may later be considered transplant eligible approximately 6 months after stopping, while renal insufficiency, the most common reason for exclusion in our series, may improve with the treatment of right heart failure.
Controlled studies also suggest caution with the use of PAH therapies in Group 3 PH. Early studies of PH therapies in lung disease did not require $\mathrm{PH}$, instead looking at whether $\mathrm{PH}$ therapies might be effective for interstitial lung diseases in general (19-22). At large, these studies were negative, and an IPF study, ARTEMIS-1, was halted early after higher rates of hospitalization and disease progression were seen with ambrisentan therapy (21). In later studies that did focus on Group $3 \mathrm{PH}$, a few showed positive results (23-25), but larger randomized controlled trials have shown either no improvement (26), or possible harm, as suggested by RISE-IIP, a randomized controlled trial of riociguat which was terminated early due to increased severe adverse event rate and mortality (27). However, severe RV dysfunction appears to have been uncommon (or not assessed) in most studies. One exception is STEP-IPF, a randomized controlled trial of sildenafil in IPF. In a post-hoc analysis, possible improvement was suggested for the subgroup of patients with $R V$ dysfunction at baseline. Nevertheless, the post-hoc nature and small subgroup size in an otherwise negative study raises concerns about whether this will be reproducible (28).

Limitations in our current study include retrospective data collection, missing data, and potentially bias in types of missing data as sicker patients may have been more likely to die prior to follow-up testing. Additional limitations include the inherent heterogeneity of the hypoxemic lung diseases and background oral therapies. Also, without a control group it is impossible to definitively determine whether patients overall benefitted or were harmed by the prostanoid therapy (or potentially both). Finally, our cohort size was small, limited by the low prevalence of the population of 

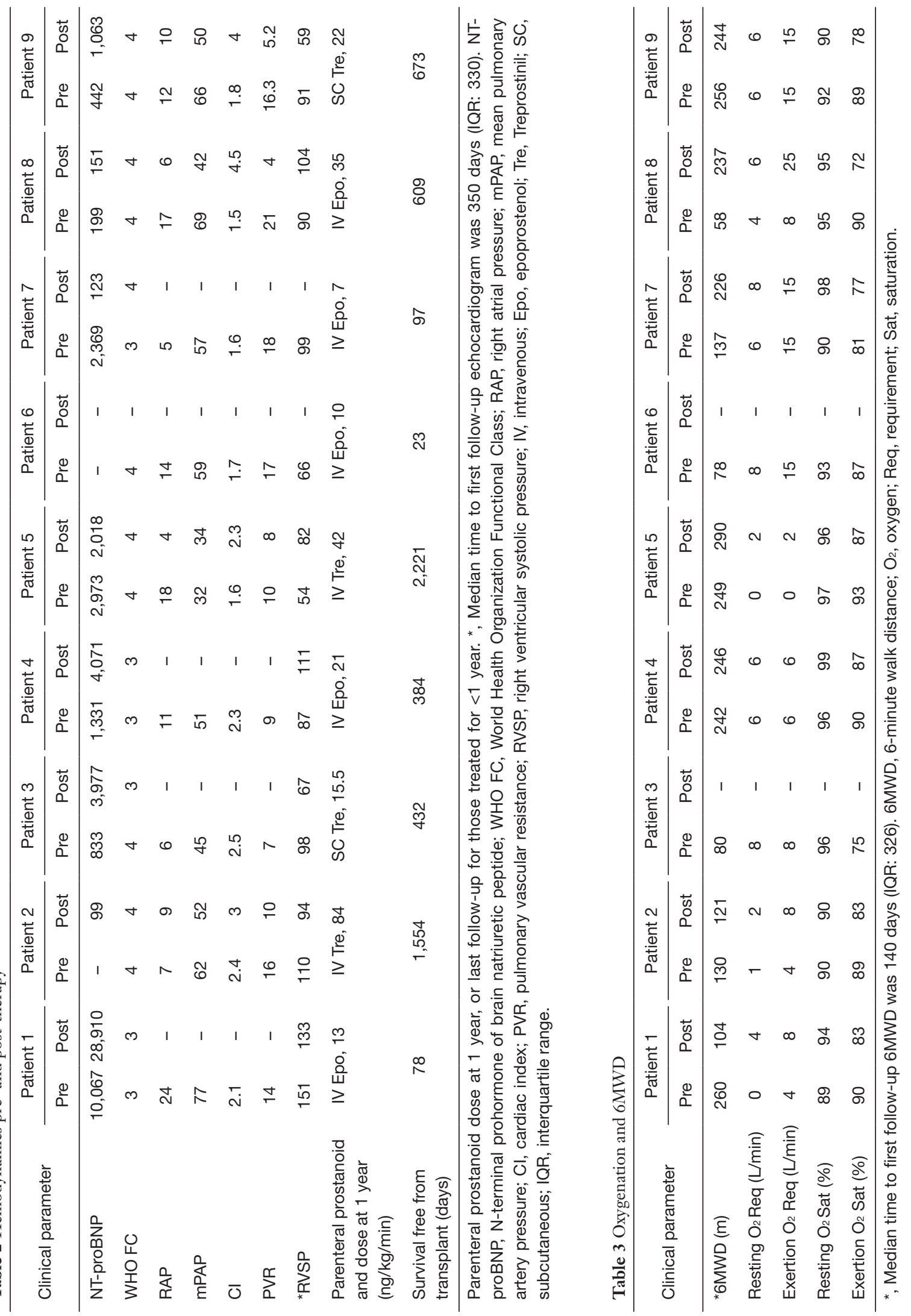

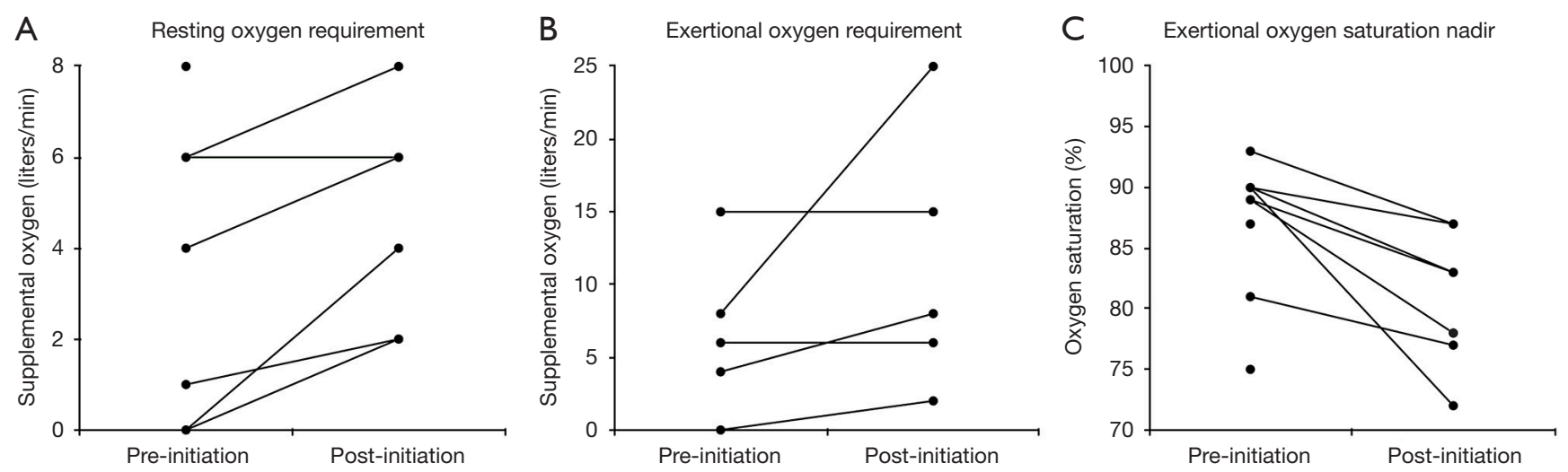

Figure 2 Clinical data obtained at initiation of parental prostanoids and at first clinical follow-up. (A) resting oxygen requirement; (B) exertional oxygen requirement; $(C)$ exertional oxygen saturation at the nadir.

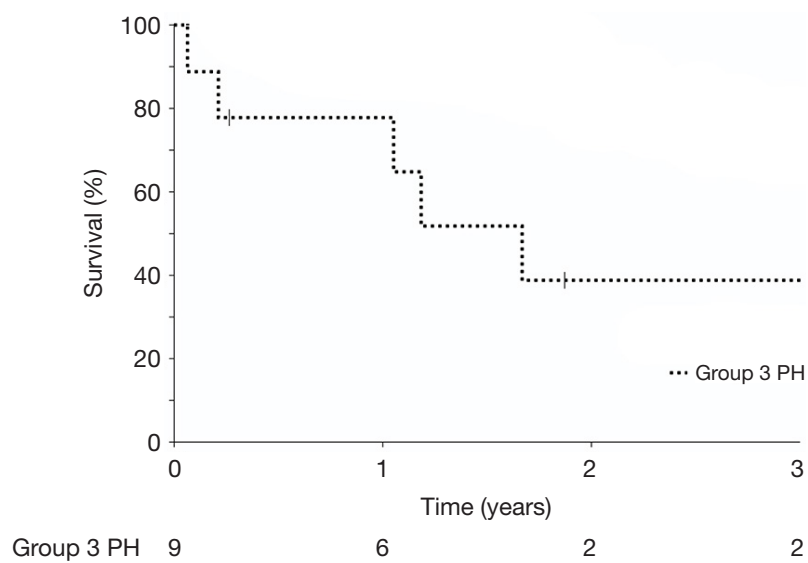

Figure 3 Kaplan-Meier survival curve demonstrating survival from time of initiation of parenteral therapy for lung disease related $\mathrm{PH}$ (Group $3 \mathrm{PH}$ ) patients. Overall survival at 1, 2, and 3 years was $78 \%, 39 \%$ and $39 \%$, respectively. $\mathrm{PH}$, pulmonary hypertension.

patients typically considered eligible for these therapies. Our study findings are therefore very preliminary.

In summary, we found no statistically significant improvement in NT-proBNP levels, exercise capacity, or functional class, while oxygen requirement at rest and oxygen saturation during exertion significantly worsened. However, the results were heterogenous. Our results suggest that parenteral prostanoids should not generally be considered in the treatment of Group $3 \mathrm{PH}$ patients.

\section{Acknowledgments}

Funding: This study was funded wholly with internal departmental funds.

\section{Footnote}

Reporting Checklist: The authors have completed the STROBE reporting checklist. Available at http://dx.doi. org/10.21037/jtd-20-1635

Data Sharing Statement: Available at http://dx.doi. org/10.21037/jtd-20-1635

Conflicts of Interest: All authors have completed the ICMJE uniform disclosure form (available at http:// dx.doi.org/10.21037/jtd-20-1635). TS reports grants from National Institutes of Health, grants from Actelion Pharmaceuticals, grants from Liquidia Technologies, grants from Bayer, grants from United Therapeutics, grants, personal fees and other from Gilead Sciences, outside the submitted work. SB reports grants from United Therapeutics, grants from Reata, grants from PhaseBio, grants from National Institutes of Health, grants from Complexa, grants from Pfizer, personal fees from Bayer, personal fees from Actelion Pharmaceuticals, outside the submitted work. FT reports grants from Liquida Technologies, grants from Bellerophon, grants from Altavant, grants from GSK, grants from Complexa, grants from PhaseBio, grants from Cyclerion, personal fees from Bayer, personal fees from Reata, personal fees from United Therapeutics, personal fees from Janssen (Actelion), personal fees from Pfizer, personal fees from Genentech, outside the submitted work. KC reports grants from Actelion, grants from SoniVie, grants from Ironwood, 
personal fees from Actelion, personal fees from United Therapeutics, personal fees from Bayer, personal fees from University of California San Diego, personal fees and other from American Heart Association, outside the submitted work. The other author has no conflicts of interest to disclose.

Ethical Statement: The authors are accountable for all aspects of the work in ensuring that questions related to the accuracy or integrity of any part of the work are appropriately investigated and resolved. Institutional review board approval was obtained from the University of Texas Southwestern Medical Center Human Research Protection Program (\#052015-041), including a waiver of informed consent. The study was conducted in accordance with the Declaration of Helsinki (as revised in 2013).

Open Access Statement: This is an Open Access article distributed in accordance with the Creative Commons Attribution-NonCommercial-NoDerivs 4.0 International License (CC BY-NC-ND 4.0), which permits the noncommercial replication and distribution of the article with the strict proviso that no changes or edits are made and the original work is properly cited (including links to both the formal publication through the relevant DOI and the license). See: https://creativecommons.org/licenses/by-nc-nd/4.0/.

\section{References}

1. Hamada K, Nagai S, Tanaka S, et al. Significance of pulmonary arterial pressure and diffusion capacity of the lung as prognosticator in patients with idiopathic pulmonary fibrosis. Chest 2007;131:650-6.

2. Hayes D, Black $S$, Tobias J, et al. Influence of pulmonary hypertension on patients with idiopathic pulmonary fibrosis awaiting lung transplantation. Ann Thorac Surg 2016;101:246-52.

3. Kimura M, Taniguchi H, Kondoh Y, et al. Pulmonary hypertension as a prognostic indicator at the initial evaluation in idiopathic pulmonary fibrosis. Respiration 2013;85:456-63.

4. Lettieri CJ, Nathan SD, Barnett SD, et al. Prevalence and outcomes of pulmonary arterial hypertension in advanced idiopathic pulmonary fibrosis. Chest 2006;129:746-52.

5. Medrek SK, Sharafkhaneh A, Spiegelman AM, et al. Admission for COPD Exacerbation Is Associated with the Clinical Diagnosis of Pulmonary Hypertension: Results from a Retrospective Longitudinal Study of a Veteran
Population. COPD 2017;14:484-9.

6. Patel NM, Lederer DJ, Borczuk AC, et al. Pulmonary hypertension in idiopathic pulmonary fibrosis. Chest 2007;132:998-1006.

7. Galiè N, Humbert M, Vachiery JL, et al. 2015 ESC/ERS Guidelines for the diagnosis and treatment of pulmonary hypertension: The Joint Task Force for the Diagnosis and Treatment of Pulmonary Hypertension of the European Society of Cardiology (ESC) and the European Respiratory Society (ERS): Endorsed by: Association for European Paediatric and Congenital Cardiology (AEPC), International Society for Heart and Lung Transplantation (ISHLT). Eur Respir J 2015;46:903-75.

8. Nathan SD, Barbera JA, Gaine SP, et al. Pulmonary hypertension in chronic lung disease and hypoxia. Eur Respir J 2019;53:1801914.

9. Trammell AW, Pugh ME, Newman JH, et al. Use of pulmonary arterial hypertension-approved therapy in the treatment of non-group 1 pulmonary hypertension at US referral centers. Pulm Circ 2015;5:356-63.

10. France AJ, Prescott RJ, Biernacki W, et al. Does right ventricular function predict survival in patients with chronic obstructive lung disease? Thorax 1988;43:621-6.

11. Hoeper MM, Benza RL, Corris P, et al. Intensive care, right ventricular support and lung transplantation in patients with pulmonary hypertension. Eur Respir J 2019;53:1801906.

12. Rose L, Prins K, Archer S, et al. Survival in pulmonary hypertension due to chronic lung disease: Influence of low diffusion capacity of the lungs for carbon monoxide. J Heart Lung Transplant 2019;38:145-55.

13. Parikh V, Bhardaj A, Nair A. Pharmacotherapy for pulmonary arterial hypertension. J Thorac Dis 2019;11:S1767-81.

14. Barst RJ, Rubin LJ, Long WA, et al. A comparison of continuous intravenous epoprostenol (prostacyclin) with conventional therapy for primary pulmonary hypertension. N Engl J Med 1996;334:296-301.

15. Saggar R, Khanna D, Vaidya A, et al. Changes in right heart haemodynamics and echocardiographic function in an advanced phenotype of pulmonary hypertension and right heart dysfunction associated with pulmonary fibrosis. Thorax 2014;69:123-9.

16. Olschewski H, Ghofrani H, Walmrath D, et al. Inhaled prostacyclin and iloprost in severe pulmonary hypertension secondary to lung fibrosis. Am J Respir Crit Care Med 1999;160:600-7.

17. Ghofrani HA, Wiedemann R, Rose F, et al. Sildenafil for 
treatment of lung fibrosis and pulmonary hypertension: a randomised controlled trial. Lancet 2002;360:895-900.

18. Günther A, Enke B, Markart P, et al. Safety and tolerability of bosentan in idiopathic pulmonary fibrosis: an open label study. Eur Respir J 2007;29:713-9.

19. King TE Jr, Behr J, Brown KK, et al. BUILD-1: a randomized placebo-controlled trial of bosentan in idiopathic pulmonary fibrosis. Am J Respir Crit Care Med 2008;177:75-81.

20. King TE Jr, Brown KK, Raghu G, et al. BUILD-3: a randomized, controlled trial of bosentan in idiopathic pulmonary fibrosis. Am J Respir Crit Care Med 2011;184:92-9.

21. Raghu G, Behr J, Brown K, et al. Treatment of idiopathic pulmonary fibrosis with ambrisentan: a parallel, randomized trial. Ann Intern Med 2013;158:641-9.

22. Raghu G, Million-Rousseau R, Morganti A, et al. Macitentan for the treatment of idiopathic pulmonary fibrosis: the randomised controlled MUSIC trial. Eur Respir J 2013;42:1622-32.

23. Vitulo P, Stanziola A, Confalonieri M, et al. Sildenafil in severe pulmonary hypertension associated with chronic

Cite this article as: Hinkamp CA, Shah T, Bartolome S, Torres F, Chin KM. Parenteral prostanoids for severe Group 3 pulmonary hypertension with right ventricular dysfunction. J Thorac Dis 2021;13(3):1466-1475. doi: 10.21037/jtd-20-1635 obstructive pulmonary disease: a randomized controlled multicenter clinical trial. J Heart Lung Transplant 2017;36:166-74.

24. Valerio G, Bracciale P, Grazia D'Agostino A. Effect of bosentan upon pulmonary hypertension in chronic obstructive pulmonary disease. Ther Adv Respir Dis 2009;3:15-21.

25. Corte TJ, Keir GJ, Dimopoulos K, et al. Bosentan in pulmonary hypertension associated with fibrotic idiopathic interstitial pneumonia. Am J Respir Crit Care Med 2014;190:208-17.

26. Zisman DA, Schwarz M, Anstrom KJ, et al. A controlled trial of sildenafil in advanced idiopathic pulmonary fibrosis. N Engl J Med 2010;363:620-8.

27. Nathan S, Behr J, Collard H, et al. RISE-IIP: riociguat for the treatment of pulmonary hypertension associated with idiopathic interstitial pneumonia. Eur Respir J 2017;50:abstr OA1985.

28. Han MK, Bach DS, Hagan PG, et al. Sildenafil preserves exercise capacity in patients with idiopathic pulmonary fibrosis and right-sided ventricular dysfunction. Chest 2013;143:1699-708. 